\title{
PELATIHAN PENINGKATAN KUALITAS EVALUASI PEMBELAJARAN BAHASA ARAB BERBASIS INFORMATION DAN COMMUNICATION TECHNOLOGY (ICT) UNTUK PENGAJAR BAHASA ARAB
}

\author{
Moh. Fery Fauzi ${ }^{1}$, Ahmad Fatoni' ${ }^{2}$, Irma Anindiati ${ }^{3}$ \\ 1,2Program Studi Pendidikan Bahasa Arab Fakultas Agama Islam, Universitas Muhammadiyah Malang \\ ${ }^{3}$ Program Pembelajaran Bahasa Arab, UIN Maulana Malik Ibrahim Malang \\ Email: mohferyfauzi@umm.ac.id
}

\begin{abstract}
Information and communication technology (ICT) have an important role in teaching and learning activities, especially in learning assessment. Instructional assessment is one of a series of learning activities aimed at correcting, controlling the extent to which learning objectives have been achieved. Instructional assessment can be done with the help of computers and the internet so that the management of learning outcomes becomes easier, faster, and real time. The technology that can be used in the assessment process is such as edmodo, google quiz, hot potatoes, quiz creator. But in reality, most learning activities that teachers use are still conventional. That is due to the lack of knowledge and mastery of teachers on the use of information and communication technology, especially in instructional assessment. Therefore, there is a need for training on the use of ICT-based Instructional assessment to improve teachers' competency. The approach method used assistance that includes socialization, workshops, training, hands-on practice, and evaluation. The results obtained state that evaluation of learning is very important for a program and purpose, both educational, learning, or training programs.

Keywords: Instructional Assessment, ICT, Arabic Language Learning
\end{abstract}

\begin{abstract}
Abstrak. Teknologi informasi dan komunikasi memiliki peranan penting dalam kegiatan belajar mengajar terutama dalam evaluasi pembelajaran. evaluasi pembelajaran merupakan salah satu rangkaian dalam kegiatan pembelajaran yang bertujuan untuk mengoresksi, mengontrol sejauh mana tujuan pembelajaran telah dicapai. Evaluasi pembelajaran dapat dilakukan dengan bantuan komputer serta internet sehingga pengelolaan hasil belajar pun menjadi lebih mudah, cepat dan real time. Adapun teknologi yang dapat digunakan dalam proses evaluasi tersebut seperti edmodo, google quiz, hot potatoes, quiz creator. Akan tetapi realitanya, kebanyakan kegiatan pembelajaran yang digunakan guru sekarang masih konvensional. Hal itu disebabkan minimnya pengetahuan dan penguasaan guru terhadap pemanfaatan teknologi informasi dan komunikasi terutama dalam evaluasi pembelajaran. Oleh sebab itu perlu adanya pelatihan pemanfaatan evaluasi pembelajaran berbasis ICT meningkatkan kompetensi guru. Metode pendekatan yang digunakan adalah pendampingan yang meliputi sosialisasi, workshop, pelatihan, praktik langsung, dan evaluasi. Hasil yang didapatkan menyatakan bahwa evaluasi pembelajaran sangat penting untuk suatu program dan tujuan, baik program pendidikan, pembelajaran, atau pun pelatihan.
\end{abstract}

Kata kunci : Evaluasi Pembelajaran, ICT, Pembelajaran Bahasa Arab,

\section{PENDAHULUAN}

Perkembangan ICT yang sangat pesat dalam satu dasa warsa terakhir ini mempengaruhi setiap aspek kehidupan. Pendidikan merupakan salah satu aspek yang terpengaruh oleh perkembangan ICT. Tidak dapat diragukan bahwa perkembangan ICT dengan berbagai aspek modernitasnya, memberikan kontribusi yang besar bagi perkembangan pendidikan pada era modern ini. Tantangan dunia dan perubahan yang cepat dalam semua aspek kehidupan sosial, ekonomi dan budaya saat ini menuntut lembaga- lembaga pendidikan untuk menjawab tantangan dunia tersebut dengan mengadakan pembelajaran yang modern dan berorientasi pada masa depan. Perkembangan ilmu pengetahuan dan teknologi telah menambah banyak hal baru yang dapat digunakan dalam memoles bidang-bidang keahlian peserta didik sehingga mereka memiliki kualifikasi yang tinggi dan siap menghadapi tantangan zaman. Secara tidak langsung hal tersebut mewajibkan manusia untuk mengenali dan menguasai teknologi tersebut (Sartika, Saluza, \& Amelia, 2017) karena ketika seseorang 
tidak mampu menguasai teknologi, dapat dipastikan orang tersebut akan kesulitan dalam beradaptasi dengan lingkungan luar. (Mulyani, Wibisono, Alawiyah, \& Warnilah, 2019). Dengan demikian, salah satu kompetensi yang menjadi tuntutan global adalah seseorang diharapkan mampu menggunakan teknologi khususnya teknologi informasi dan komunikasi dalam kehidupan profesional maupun kehidupan personal.

Teknologi informasi dan komunikasi memiliki beberapa fungsi, yaitu: memudahkan seseorang dalam berkomunikasi guna untuk mendapatkan informasi, karena orang dapat berkomunikasi tanpa harus bertemu dan dapat memperoleh informasi tanpa harus datang ke tempat; (2) mengembangkan kemampuan dan kesadaran masyarakat, khususnya kesadaran bahwa teknologi semakin berkembang dan dapat dimanfaatkan untuk kebaikan; (3) menunjang dan meningkatkan kualitas pendidikan baik informasi, pendidikan, dan keterampilam; (4) meningkatkan kualitas dan kuantitas layanan publik dalam kegiatan pembelajaran, dan (5) mendorong berdemonstrasi dalam membuka peluang bisnis, mengingat media ini dapat dimanfaatkan untuk kompetisi memperoleh peluang tanpa melihat hubungan khusus sebelumnya. (Sutiyah, 2013).

Teknologi informasi dan komunikasi memiliki peranan penting dalam dunia pendidikan (Fuqon, 2019). seperti kegiatan belajar mengajar terutama dalam evaluasi pembelajaran.(Setia Asih, Okyranida, \& Aqil, 2019) Evaluasi pembelajaran merupakan salah satu rangkaian dalam kegiatan pembelajaran yang bertujuan untuk mengoresksi, mengontrol sejauh mana tujuan pembelajaran telah dicapai. Seperti yang dikatakan oleh (Djiwandono 2011) yakni menyatakan bahwa upaya untuk memastikan ketercapaian tujuan pembelajaran tersebut dilakukan dengan menyelenggarakan serangkaian evaluasi terhadap hasil belajar dalam kurun waktu tertentu. Adapun menurut .(Zainal Arifin, 2014). Evaluasi merupakan salah satu kompetensi yang harus dikuasai oleh guru. Seorang guru memiliki tugas yang sangat penting dalam prosese kegiatan pembelajaran. (Buhun \&
Purwadi, Agus, 2019). Kompetensi ini sejalan dengan tugas dan tanggung jawab guru dalam pembelajaran, yaitu mengevaluasi pembelajaran termasuk di dalamnya melaksanakan penilaian proses dan hasil belajar. Kompetensi tersebut sejalan pula dengan instrumen penilaian kemampuan guru, yang salah satu indikatornya adalah melakukan evaluasi pembelajaran.

Evaluasi pembelajaran dapat dilakukan dengan bantuan komputer serta internet sehingga pengelolaan hasil belajar pun menjadi lebih mudah, cepat dan real time. Evaluasi berbasis komputer diharapkan mampu memberikan hasil evaluasi yang tepat dan cepat. Biaya dan waktu untuk persiapan dan pelaksanaan tes dapat dimanfaatkan seefisien dan seefektif mungkin (Setemen, 2010)

Seiring dengan perkembangan zaman dan teknologi, hampir pada setiap aktivitas pendidikan memanfaatkan teknologi sebagai alat bantu utamanya untuk menunjang pelaksanaan efektivitas kegiatan pembelajaran. Selain itu, perkembangan internet juga menjadi salah satu hal yang menimbulkan adanya kebutuhan untuk menguasai teknologi semakin tinggi (Mulyani et al., 2019). Data dari APJII menyebutkan bahwa penggunaan internet di Indonesia sudah mencapai angka 88,1 juta (Tim APJII, 2016). Jika dibandingkan dengan 252,4 juta penduduk Indonesia, dapat dikatakan bahwa pengguna internet di negara Indonesia mencapai 34,9\%. Hal ini menunjukkan bahwa pengguna internet di Indonesia sangat banyak. (Tundjungsari \& Suhaeri, 2018).

Di bidang pendidikan, media internet sering kali digunakan sebagai media pembelajaran yakni alat bantu untuk memperagakan fakta, konsep, prinsip, atau prosedur tertentu agar tampak lebih nyata atau kongkrit. (Agustina, Astuti, \& Nugraha, 2018). Terlebih lagi melihat penggunaan internet yang sangat pesat dikalangan anak-anak terutama bagi siswa khususnya Sekolah Menengah Atas atau sederajad yang mencapai 64,7 \% (APJII, 2105).

Adapun teknologi yang dapat digunakan dalam proses evaluasi tersebut bisa berupa komputer atau laptop, tablate dan handphone (hp) untuk meningkatkan minat siswa untuk 
belajar (Fauzi \& Anindiati, 2019) dengan memanfaatkan aplikasi yang tersedia seperti edmodo, google quiz, hot potatoes, quiz creator yang mana aplikasi-aplikasi tersebut hanya bisa diakses melalui internet. Aplikasi-aplikasi tersebut dapat menjadi salah satu pilihan sebagai media evaluasi dalam pembelajaran yang cukup efektif.

Akan tetapi realitanya, kebanyakan kegiatan pembelajaran yang digunakan guru sekarang masih konvensional. Yaitu siswa mengerjakan soal dengan menulis jawabannya di lembar jawaban yang sudah disediakan. Sehingga pada waktu mengerjakan banyak terjadi kesalahan, seperti jumlah soal yang tidak sesuai dengan waktu pengerjaan, waktu tidak sesuai dengan rencana, lamanya waktu dalam pengoreksian, terjadinya kecurangan dalam mengerjakan soal seperti terjadinya pencontekan (Rahayu \& Listiyadi, 2014). Hal itu disebabkan minimnya pengetahuan dan penguasaan guru terhadap pemanfaatan teknologi informasi dan komunikasi terutama dalam evaluasi pembelajaran. Oleh sebab itu perlu adanya pelatihan pemanfaatan evaluasi pembelajaran berbasis ICT untuk guru.

Oleh karena itu, kegiatan pengabdian masyarakat yang telah dilaksanakan ini memiliki peran dalam meningkatkan kompetensi guru. Dalam kesempatan kali ini, tim dosen Universitas Muhammadiyah Malang Program Studi Pendidikan Bahasa Arab Fakultas Agama Islam Universitas Muhammadiyah Malang ingin berkontribusi keilmuan dan pengalaman yang dimiliki untuk membantu para guru dengan program "PELATIHAN PEMANFAATAN EVALUASI PEMBELAJARAN BAHASA ARAB BERBASIS INFORMATION DAN COMMUNICATION TECHNOLOGY (ICT) UNTUK GURU MGMP BAHASA ARAB”.

Target luaran yang dihasilkan diselenggarakannya kegiatan pengabdian ini adalah produk dan jasa, yang dapat diuraikan sebagai berikut:

1) Produk berupa booklet pengembangan evaluasi pembelajaran berbasis TIK yang kemudian diharapkan diimplementasikan secara kontinyu di sekolah mitra.

2) Jasa berupa adanya peningkatan kompetensi civitas akademika calon pengajar bahasa Arab dalam pembuatan dan pengelolaan evaluasi pembelajaran berbasis TIK.

3) Produk berupa laporan.

\section{METODE PELAKSANAAN}

Pelatihan kepada guru-guru ini dilaksanakan di Universitas Muhammadiyah Malang, yang beralamat di Jl. Raya Tlogomas, Lowokwaru, Kota Malang Jawa Timur pada tanggal 20 April 2019.

Peserta yang mengikuti pelatihan pemanfaatan evaluasi pembelajaran berbasis ICT ini berjumlah kurang lebih 20 orang yang berasal dari bebrbagai instansi, mulai dari guru SD sampai dengan guru SMA.

Metode pendekatan yang digunakan dalam kegiatan pengabdian ini sepenuhnya disesuaikan dengan hasil analisis situasi terhadap permasalahan prioritas yang disepakati untuk diselesaikan bersama dengan mitra yang merupakan calon pengajar bahasa Arab. Metode pendekatan yang digunakan adalah pendampingan yang meliputi sosialisasi, workshop, pelatihan, praktik langsung, dan evaluasi. Metode ini dapat memberikan peran lebih kepada pada civitas akademika mitra sehingga mereka lebih memiliki keterampilan dan kompetensi dalam mengembangkan evaluasi pembelajaran berbasis TIK untuk memudahkan pengelolaan hasil belajar peserta didik.

Berikut uraian tahapan kegiatan, metode pelaksanaan beserta materi kegiatan pelatihan telah terlaksana sesuai dengan urutan kegiatan sebagaimana ditunjukkan pada tabel 1 . 
Tabel 1. Tahapan Kegiatan, Metode Pelaksanaan Pengabdian dan Materi

\begin{tabular}{clll}
\hline No & \multicolumn{1}{c}{ Kegiatan PPMI } & \multicolumn{1}{c}{ Metode } & \multicolumn{1}{c}{ Materi } \\
\hline 1 & $\begin{array}{l}\text { Sosialisasi (Penyampaian materi } \\
\text { pengantar dan penyamaan } \\
\text { persepsi) kepada mitra }\end{array}$ & Diskusi dan sosialisasi & \\
\hline 2 & $\begin{array}{l}\text { Sosialisasi dan workshop terkait } \\
\text { dengan konsep pengembangan } \\
\text { evaluasi pembelajaran berbasis }\end{array}$ & $\begin{array}{l}\text { Diskusi, pelatihan, } \\
\text { workshop }\end{array}$ & $\begin{array}{l}\text { 1. Edmodo (2 jam) } \\
\text { 2. Google Quiz (2 jam) }\end{array}$ \\
& 3IK & 3. Hot Potatoes (2 jam) \\
\hline 3 & $\begin{array}{l}\text { Pendampingan implementasi } \\
\text { pengembangan evaluasi } \\
\text { pembelajaran berbasis TIK }\end{array}$ & Praktik, diskusi, & \\
\hline 4 & Monitoring dan evaluasi & Dreator (2 jam)
\end{tabular}

a. Sosialisasi Dan Workshop Terkait Dengan Konsep Pengembangan Evaluasi Pembelajaran Berbasis TIK

Sosialisasi dan workshop ini dilakukan untuk memberi bekal pemahaman/teoritis dan praktis kepada civitas akademika sekolah. Diskusi, sharing dan workshop pengalaman terkait pengembangan evaluasi pembelajaran berbasis TIK.

b. Pendampingan

Implementasi

Pengembangan Evaluasi Pembelajaran

Berbasis TIK

Kegiatan pendampingan implementasi pengembangan evaluasi pembelajaran berbasis TIK ini merupakan bagian terpenting dari pengabdian ini karena menjadi tolok ukur keberhasilan. Setelah tahap pemberian sosialisasi dan workshop maka civitas akademika sekolah akan mempraktikkan berbagai informasi yang telah mereka kuasai.

\section{HASIL DAN PEMBAHASAN}

\section{A. HASIL}

\section{Pelaksanaan Pengabdian}

Pengabdian kepada masyarakat ini berbentuk pelatihan dan workshop pengembangan evaluasi pembelajaran bahasa Arab berbasis teknologi informasi dan komunikasi (TIK) untuk mahasiswa di
Universitas Muhammadiyah Malang. Adapun pelatihan dan workshop dilaksanakan pada:

$\begin{array}{ll}\text { Hari } & : \text { Sabtu } \\ \text { Tanggal } & : \text { 20 April } 2019 \\ \text { Tempat } & : \text { Gedung Kuliah Bersama (GKB) } \\ & \text { IV lantai 4 Universitas } \\ & \text { Muhammadiyah Malang } \\ \text { Waktu } & : 08.30-16.30\end{array}$

Kegiatan pengabdian yang dilaksanakan ini diawali oleh prosesi pembukaan oleh pihak dekanat Fakultas Agama Islam Universitas Muhammadiyah Malang yang diwakili oleh Wakil Dekan II, Bapak Drs. M. Sarif, M.Ag. Selain itu, dalam acara seremonial juga dihadiri oleh Ketua Program Studi Pendidikan Bahasa Arab.

\section{Mitra Pengabdian}

Mitra pengabdian masyarakat adalah para guru dan pengajar Bahasa Arab yang tergabung dalam Musyawarah Guru Mata Pelajaran (MGMP) Kota Malang, Kabupaten Malang, dan Kota Batu. Selain itu, para guru ISMUBA juga terlibat aktif menjadi mitra yang perlu meningkatkan kompetensi di bidang pedagogik agar manajemen kelas menjadi baik dan tujuan pembelajaran dapat tercapai melalui evaluasi pembelajaran yang baik.

Pelatihan evaluasi pembelajaran berbasis digital juga dihadiri oleh beberapa dosen Program Studi Pendidikan Bahasa Arab dari UIN Maulana Malik Ibrahim Malang, UIN Sultan 
Syarif Kasim Riau, dan IAIN Samarinda. Para dosen yang mengetahui informasi tentang kegiatan pelatihan ini tertarik untuk hadir dan belajar tentang evaluasi pembelajaran berbasis digital. Selain itu, ada juga beberapa guru di luar MGMP Bahasa Arab Malang Raya yang juga hadir dan antusias mengikuti pelatihan (data peserta terlampir). Acara sukses terselenggara karena adanya kerja sama yang baik dari berbagai pihak.

\section{Materi Pengabdian}

Materi dan gambaran tentang IPTEK yang telah ditransfer kepada mitra adalah materi tentang perangkat lunak (Software) yang bisa dimanfaatkan untuk membuat evaluasi pembelajaran secara real time dengan menggunakan teknologi informasi dan komunikasi (materi disusun dalam bentuk modul pelatihan dan terlampir). Secara detail, tahapan penyampaian materi dijabarkan berikut ini.

a. Sosialisasi (Penyampaian Materi Pengantar dan Penyamaan Persepsi)

Kegiatan sosialisasi (penyampaian materi pengantar dan penyamaan persepsi) dilakukan agar ada persamaan persepsi dengan mitra terhadap masalah-masalah yang dihadapi dan solusi permasalahan. Kegiatan ini menjadi titik awal yang sangat penting guna mengetahui peran dan tanggung jawab masing-masing pihak dalam menyelesaikan masalah yang dihadapi.

b. Pelatihan dan Workshop Terkait Dengan Konsep Pengembangan Evaluasi
Pembelajaran Berbasis TIK

Pelatihan dan workshop ini dilakukan untuk memberi bekal pemahaman teoritis dan praktis kepada civitas akademika sebagai calon pengajar bahasa Arab. Diskusi, sharing, dan workshop terkait pengembangan evaluasi pembelajaran berbasis TIK dilakukan agar mitra memiliki kompetensi di bidang pembelajaran bahasa Arab dan evaluasi pembelajarannya.

c. Pendampingan

Pengembangan Evaluasi Pembelajaran Berbasis TIK

Kegiatan pendampingan implementasi pengembangan evaluasi pembelajaran berbasis TIK merupakan bagian terpenting dari pengabdian ini karena menjadi tolok ukur keberhasilan. Setelah tahap pemberian sosialisasi maka dilakukan workshop bagi civitas akademika sebagai mitra pengabdian yang akan mempraktikkan berbagai informasi yang telah mereka kuasai.

\section{B. PEMBAHASAN}

\section{Pelaksanaan Pengabdian}

Kegiatan pengabdian yang dilaksanakan ini diawali dengan seremonial pembukaan oleh pihak dekanat Fakultas Agama Islam Universitas Muhammadiyah Malang yang diwakili oleh Wakil Dekan II, Bapak Drs. M. Sarif, M.Ag. Selain itu, dalam acara seremonial juga dihadiri oleh Ketua Program Studi Pendidikan Bahasa Arab.

Wakil Dekan II Fakultas Agama Islam dalam sambutannya menyampaikan pentingnya materi yang disampaikan dalam pelatihan dan workshop. Kegiatan ini diharapkan mampu memberikan bekal kepada mitra pengabdian masyarakat dalam meningkatkan kompetensi pedagogik sebagai pengajar bahasa Arab.

\section{Tingkat Kepuasan Mitra Pengabdian}

Evaluasi pembelajaran sangat penting untuk suatu program dan tujuan, baik program pendidikan, pembelajaran, atau pun pelatihan. Secara umum, tujuan evaluasi pembelajaran adalah untuk mengetahui tingkat ketercapaian program yang sudah dijalankan seperti program pembelajaran bahasa Arab. Evaluasi pembelajaran harus dilakukan agar di masa yang akan datang program yang dicanangkan bisa dicapai dan diukur.

Pelatihan dan workshop tentang pengembangan evaluasi pembelajaran berbasis TIK dirancang untuk membekali para mahasiswa sebagai calon pengajar bahasa Arab di bidang pedagogik. Mitra pengabdian mayoritas menyatakan sangat puas dengan penyelenggaraan pelatihan dan workshop ini. Berikut hasil survei yang dilakukan oleh narasumber pengabdian masyarakat. 


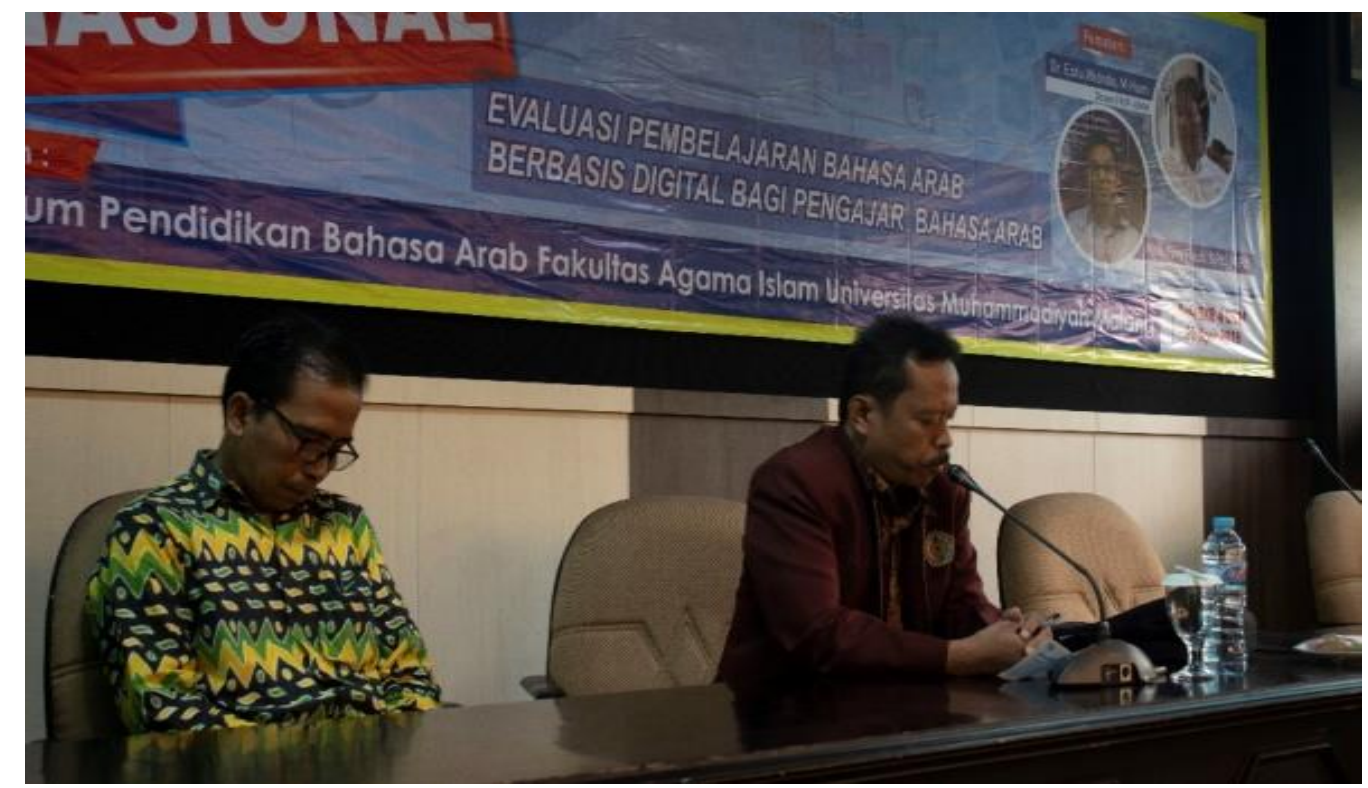

Gambar 1. Pembukaan Pelatihan oleh Wakil Dekan II FAI UMM

\section{Apakah pelatihan ini bermanfaat bagi anda?}

\section{0 responses}

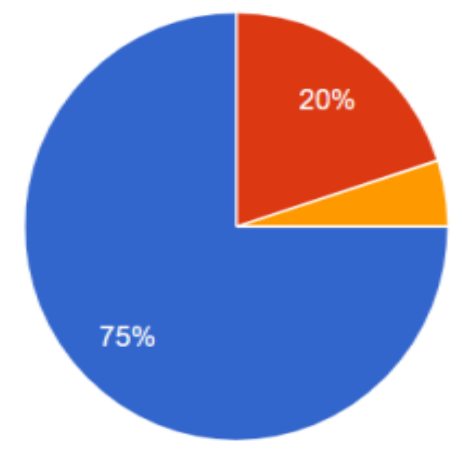

Sangat Bermanfaat

Bermanfaat

Biasa Saja

Tidak Bermanfaat

Sangat Tidak Bermanfaat

\section{Gambar 2. Hasil Survei Tingkat Kepuasan dan Asas Kebermanfaatan Pelatihan}

Dari hasil evaluasi dan survei pelatihan dan workshop tentang pelatihan pengembangan evaluasi pembelajaran bahasa Arab, $75 \%$ responden menyatakan bahwa kegiatan ini sangat bermanfaat. 20\% menyatakan kegiatan ini bermanfaat dan $5 \%$ menyatakan biasa saja. Hal ini mengindikasikan bahwa mayoritas mitra pengabdian sangat puas karena mendapatkan banyak manfaat dari kegiatan ini.

Hal tersebut dapat dilihat berdasarkan pendapat dari guru-guru yang mengikuti pelatihan, yaitu pada Tabel 2. Dari saran yang disampaikan mitra tentang kegiatan pelatihan dan workshop diketahui bahwa mitra sangat berharap bahwa kegiatan ini bisa diselenggarakan lagi dengan waktu yang lebih lama. Berikut salah satu saran dari mitra masyarakat yang disampaikan melalui google form yang disediakan oleh narasumber pengabdian masyarakat. "Kesan: bisa menambah pengetahuan baru dan membantu guru dalam melaksanakan tugasnya. Saran: untuk waktu penjelasan mengenai penerapan evaluasi pembelajaran berbasis ICT ini diperpanjang lagi." Mitra 1

"Sangat memuaskan dan dapat menambah wawasan dan juga dapat membantu jika suatu saat nanti materi ini dibutuhkan." Mitra 
Tabel 2. Tanggapan peserta pelatihan pengabdian

\begin{tabular}{lll}
\hline No & Nama & Tanggapan \\
\hline 1 & Hermi Ismawati & $\begin{array}{l}\text { Materi yang cukup bagus di era milenial 4.0 ini, } \\
\text { dikarenakan kita sangat perlu sekali upgrade ilmu }\end{array}$ \\
\hline 2 & Ulfa Aulia & $\begin{array}{l}\text { Materi sangat bagus untuk pengembangan evaluasi } \\
\text { pembelajaran bahasa Arab di Madrasah di era digital } \\
\text { ini }\end{array}$ \\
\hline 3 & Ahmad Afwan Yazid, S.Pd & Menjadikan guru-guru lebih memahami IT \\
\hline 4 & Siti Nurul Fitriani & $\begin{array}{l}\text { Sangat Bermanfaat untuk pengembangan evaluasi di } \\
\text { madrasah kami }\end{array}$ \\
\hline
\end{tabular}

\section{Tingkat Ketercapaian Materi Pengabdian}

Mitra pengabdian masyarakat dapat dikategorikan menjadi tiga kelompok, yaitu: 1) Guru MGMP Bahasa Arab Malang Raya dan ISMUBA, 2) Pengajar Bahasa Arab di luar MGMP Malang Raya, dan 3) Dosen Pendidikan Bahasa Arab dari UIN Maulana Malik Ibrahim Malang, UIN Sultan Syarif Kasim Riau, dan IAIN Samarinda. Mitra pengabdian merupakan pengajar bahasa Arab yang perlu meningkatkan kompetensi di bidang pedagogik agar manajemen kelas menjadi baik dan tujuan pembelajaran dapat tercapai.

Materi pengembangan evaluasi pembelajaran bahasa Arab berbasis TIK disampaikan langsung oleh narasumber yang merupakan pengusul program pengabdian masyarakat. Sebelum itu, materi teoretis juga disampaikan oleh Dr. Estu
Widodo, M.Hum. Beliau pakar di bidang evaluasi pembelajaran Universitas Muhammadiyah Malang.

Kegiatan sukses terselenggara karena adanya kerja sama yang baik dari berbagai pihak. Berikut respon dari mitra pengabdian.

"Sangat bermanfaat dan menambah pengetahuan baru mengenai PENERAPAN

EVALUASI PEMBELAJARAN BERBASIS TIK (ICT)." Mitra

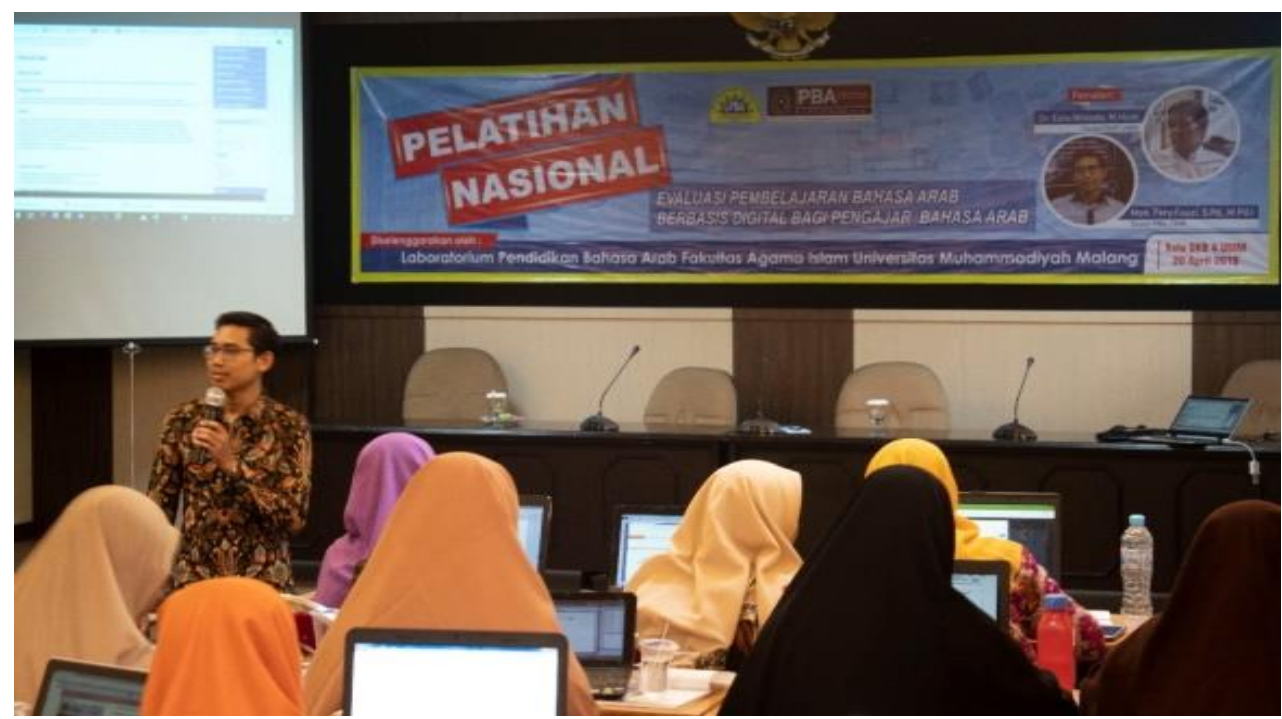

Gambar 3. Narasumber dan Pengusul Program Pengabdian Masyarakat Menyampaikan Materi tentang Pengembangan Evaluasi Pembelajaran Bahasa Arab Berbasis Digital 


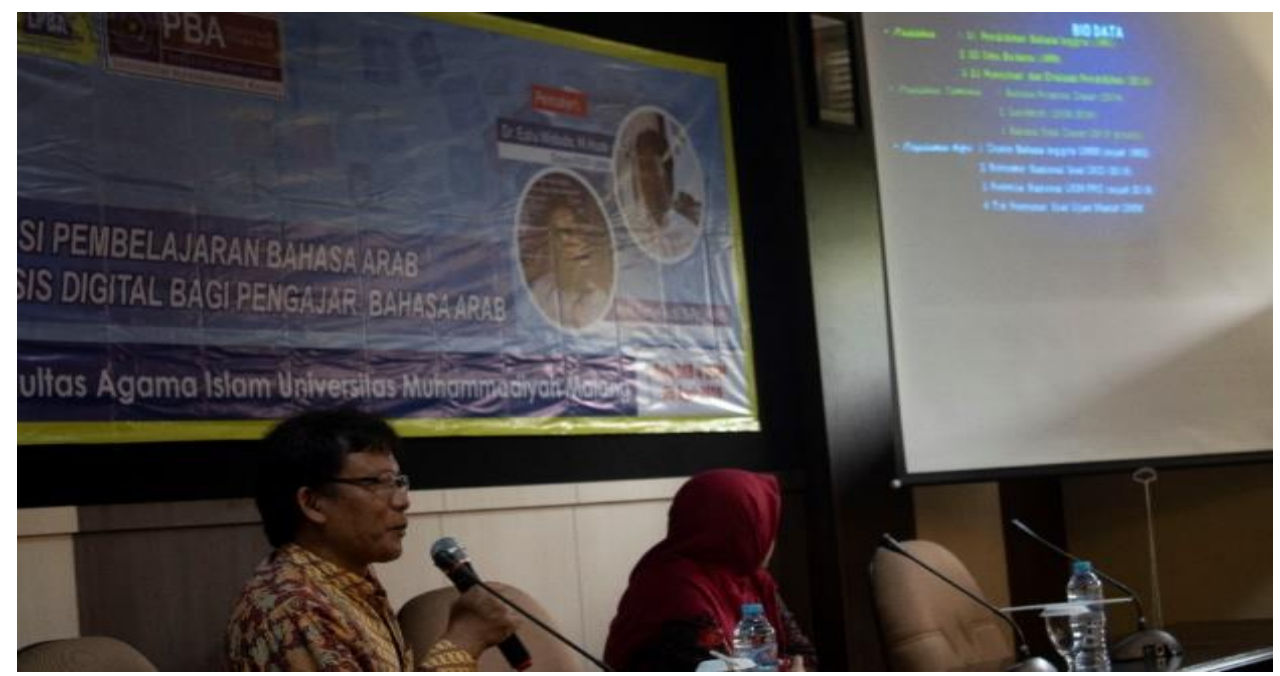

Gambar 4. Dr. Estu Widodo, M.Hum Menyampaikan Materi tentang Pengembangan Evaluasi Pembelajaran Bahasa Arab Berbasis Digital

Tabel 3. Tingkat Ketercapaian Materi Pelatihan \& Workshop

\begin{tabular}{|c|c|c|c|c|}
\hline No & Kegiatan & Indikator & Ketercapaian & Keterangan \\
\hline \multirow[t]{3}{*}{1} & Sosialisasi & Publikasi kegiatan & $100 \%$ & Tercapai \\
\hline & & Pendaftaran peserta & $100 \%$ & $\begin{array}{l}>20 \text { peserta (target } \\
20 \text { peserta) }\end{array}$ \\
\hline & & Partisipasi & $100 \%$ & $\begin{array}{l}>20 \text { peserta (target } \\
20 \text { peserta) }\end{array}$ \\
\hline \multirow[t]{2}{*}{2} & $\begin{array}{l}\text { Pelatihan } \\
\text { Workshop }\end{array}$ & Penyampaian Teori & $100 \%$ & Terlaksana \\
\hline & & $\begin{array}{l}\text { Praktik Pengembangan } \\
\text { Evaluasi Berbasis ICT }\end{array}$ & $100 \%$ & Terlaksana \\
\hline 3 & $\begin{array}{l}\text { Evaluasi Pelatihan } \\
\text { \& Workshop }\end{array}$ & $\begin{array}{l}\text { Survei terhadap mitra tentang } \\
\text { pelaksanaan pelatihan \& } \\
\text { workshop }\end{array}$ & $100 \%$ & Terlaksana \\
\hline
\end{tabular}

Dari tabel di atas diketahui bahwa tingkat ketercapaian materi adalah $100 \%$. Kegiatan pengabdian dirancang mulai dari sosialisasi, pelatihan \& workshop, dan evaluasi pelatihan. Sosialisasi sukses terlaksana dengan indikator ketercapaian $100 \%$ mulai dari publikasi kegiatan, pendaftaran peserta, dan jumlah partisipasi dari mitra pengabdian masyarakat. Pelatihan dan workshop juga terlaksana $100 \%$ dengan indikator penyampaian materi secara teoritis dan dilanjutkan praktik. Sementara itu, tahap akhir adalah evaluasi kegiatan juga telah dilaksanakan dengan menggunakan media google form yang diisi dengan sistem dalam jaringan (daring).

\section{SIMPULAN DAN SARAN}

Evaluasi pembelajaran sangat penting untuk suatu program dan tujuan, baik program pendidikan, pembelajaran, atau pun pelatihan. Secara umum, tujuan evaluasi pembelajaran adalah untuk mengetahui tingkat ketercapaian program yang sudah dijalankan seperti program pembelajaran bahasa Arab. Evaluasi pembelajaran harus dilakukan agar di masa yang akan datang program yang dicanangkan bisa dicapai dan diukur.

Teknologi informasi dan komunikasi memiliki peranan penting dalam kegiatan belajar mengajar terutama dalam evaluasi pembelajaran. evaluasi pembelajaran merupakan salah satu rangkaian dalam kegiatan pembelajaran yang bertujuan untuk mengoresksi, mengontrol sejauh mana tujuan pembelajaran telah dicapai. Evaluasi pembelajaran dapat dilakukan dengan bantuan komputer serta internet sehingga 
pengelolaan hasil belajar pun menjadi lebih mudah, cepat dan real time.

Kegiatan pengabdian masyarakat ini bisa dilaksanakan secara kontinyu setiap tahun karena kegiatan banyak manfaatnya. Di antara manfaat yang bisa didapatkan dari pengabdian kepada masyarakat adalah:

1. Memberikan sumbangsih keilmuan bagi masyarakat

2. Memberikan kontribusi di bidang teknologi komunikasi dan informasi

3. Memberikan ruang untuk saling berbagi

\section{DAFTAR PUSTAKA}

Agustina, I., Astuti, D., \& Nugraha, A. M. (2018). Pengembangan Pembelajaran ELearning Dengan Web Log. 3, 165-169. https://doi.org/http://doi.org/10.25273/jta.v3 i 2.2806

APJII. (2015). Profil Pengguna Internet Indonesia 2014. Jakarta: : Asosiasi Penyelenggara Jasa Internet Indonesia.

Arifin, Z. (2014). Evaluasi Pembelajaran (Prinsip, Teknik, dan Prosedur) (keenam). Bandung: PT Remaja Rosdakarya Offset.

Buhun, M. F., \& Purwadi, Agus, M. F. F. (2019). The Influence of Teams Games Tournament ( TGT ) toward Students 'Interest in Arabic

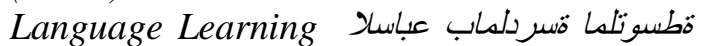

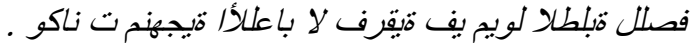

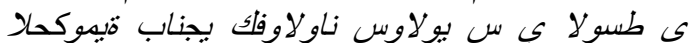

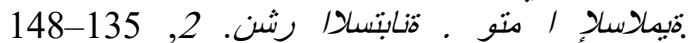
https://doi.org/10.222.19/jiz.v2i2.9986

Djiwandono, S. (2011). Tes Bahasa: Pegangan bagi Pengajar Bahasa. Jakarta: Indeks.

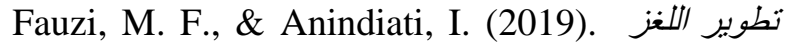
الرقمي لمادة التطبيق الصرفي 1 على الهاتف المحمول كالتدربات الإضافية خارج الفصل الدراسي التيكي XXV(1), 129-140.

https://doi.org/https://doi:org/10.15408/bat. v25i1.11

Fuqon, M. R. \& M. F. F. (2019). The Values of Educational Character in the Arabic Temples of Qasidah Burdah by Imam Bushiri. 2(2019), 67-76. https://doi.org/10.22219/jiz.v2i1.8327

Ibrahim, H. (1987). Al-Ittijaahaat Al-Mu'asirah fi Tadris Al-Lughah Al-Arabiyah wa AlLughah Al-Hayyah Al-Ukhraa li Ghairi AnNatiqiina biha. Kairo: Karya Ilmiah yang tidak dipublikasikan.

Mulyani, Y. S., Wibisono, T., Alawiyah, T., \& Warnilah, A. I. (2019). Pelatihan Komputer Dasar Untuk Mendukung Proses Kegiatan
Belajar Mengajar (Kbm) Bagi Guru-Guru Ra/Tpq/Dta Al-Ishlaah Kota Tasikmalaya. Jurnal Abdimas BSI: Jurnal Pengabdian Kepada Masyarakat, 2(2), 234-240. https://doi.org/10.31294/jabdimas.v2i2.576 8

Rahayu, E. E., \& Listiyadi, A. (2014). Pengembangan Alat Evaluasi Pembelajaran Berbasis Information and Communication Technologies (ICT) pada Materi Mengelola Dokumen Transaksi. Jurnal Pendidikan Akutansi, 2(2), 1-7.

Sartika, D., Saluza, I., \& Amelia, M. (2017). Pelatihan Pembuatan E-Learning Sebagai Media Pembelajaran Bagi Siswa Di Smp Negeri 29 Palembang. 1(2), 96-100.

Setemen, K. (2010). Pengembangan Evaluasi Pembelajaran Online. Jurnal Pendidikan Dan Pengajaran, 43(3), 207-214. https://doi.org/10.23887/jppundiksha.v43i3. 124

Setia Asih, D. A., Okyranida, I. Y., \& Aqil, D. I. (2019). Meningkatkan Minat Belajar Fisika Smp Dan Smk Nusa Bhakti Sawangan Depok Melalui Teknologi Media Robotik. Jurnal Terapan Abdimas, 4(2), 113. https://doi.org/10.25273/jta.v4i2.4797

Sutiyah. (2013). Upaya Guru Sejarah Dalam Menyiasati. 23(1).

Tundjungsari, V., \& Suhaeri, S. (2018). Pelatihan Pembuatan Blog untuk Pengembangan Media Pembelajaran di Sekolah Menengah Atas dan Kejuruan. JPP IPTEK (Jurnal Pengabdian Dan Penerapan IPTEK), 2(1), 15. https://doi.org/10.31284/j.jppiptek.2018.v2i1.225 